Check for updates

Cite this: RSC Adv., 2019, 9, 12365

Received 31st January 2019

Accepted 10th April 2019

DOI: 10.1039/c9ra00822e

rsc.li/rsc-advances

\section{Novel asymmetric photodimerization reaction of coumarin derivatives bearing a chiral 2- oxazolidinone auxiliary $\dagger$}

\author{
Kennosuke Itoh, (D) *ab Fumiya Odate, ${ }^{\mathrm{C}}$ Takuma Karikomi, ${ }^{\mathrm{d}}$ Keishi Obe, ${ }^{\mathrm{e}}$ \\ Tsutomu Miyamori, ${ }^{f}$ Hideaki Kamiya, ${ }^{f}$ Kenji Yoza, ${ }^{9}$ Kenichiro Nagai, (iD b \\ Hideaki Fujii, (D) *ab Hiroyuki Suga (D) ${ }^{* f}$ and Ken Tokunaga (DD *h
}

\begin{abstract}
A novel asymmetric photodimerization reaction of coumarin derivatives bearing the (S)-4-benzyl-2oxazolidinone auxiliary provides only the syn-head-to-tail (syn-HT) dimer with moderate diastereoselectivity (up to $75: 25$ ). The mechanism of complete syn-HT selectivity and moderate diastereoselectivity is proposed based on the result of density functional theory (DFT) calculation. The benzyl group of the (S)-4-benzyl-2-oxazolidinone auxiliary in combination with a Lewis acid exerts effective diastereofacial shielding of the reaction site.
\end{abstract}

The photodimerization reactions of coumarin derivatives have been recognized as attractive photochemical transformation reactions in terms of their photophysical properties as well as their photochemical properties, from the theoretical point of view. ${ }^{\mathbf{1}}$ Recently, photodimerization reactions of coumarins have become increasingly important in several progressive research areas, e.g., drug delivery by the use of coumarin-modified mesoporous silica MCM-41 ${ }^{2 a}$ and the use of coumarinmodified polymeric nanoparticles, ${ }^{2 b, 2 c}$ chemical biology, ${ }^{2 d}$ 3D cell culture, ${ }^{2 e}$ photopatterning of ion gels, ${ }^{2 f}$ reversible twophoton optical data storage, ${ }^{2 g}$ nanolithography, ${ }^{2 h}$ polyoxometalate-containing materials, ${ }^{2 i}$ single-chain nanoparticles,${ }^{2 j}$ gelators, ${ }^{2 k}$ and optically active polymers. ${ }^{2 l}$ Although $[2+2]$ photodimerization reactions of coumarin derivatives are useful photochemical reactions, difficulties in controlling head-

${ }^{a}$ Laboratory of Medicinal Chemistry, School of Pharmacy, Kitasato University, 5-9-1 Shirokane, Minato-ku, Tokyo 108-8641, Japan. E-mail: itok@pharm.kitasato-u.ac.jp ${ }^{b}$ Medicinal Research Laboratories, School of Pharmacy, Kitasato University, 5-9-1 Shirokane, Minato-ku, Tokyo 108-8641, Japan

${ }^{c}$ Applied Chemistry and Chemical Engineering Program, Graduate School, Kogakuin University, 2665-1 Nakano, Hachioji, Tokyo 192-0015, Japan

${ }^{d}$ Department of Applied Chemistry, Faculty of Engineering, Kogakuin University, 26651 Nakano, Hachioji, Tokyo 192-0015, Japan

${ }^{e}$ Department of Applied Chemistry, School of Advanced Engineering, Kogakuin University, 2665-1 Nakano, Hachioji, Tokyo 192-0015, Japan

${ }^{f}$ Department of Materials Chemistry, Faculty of Engineering, Shinshu University, 4-171 Wakasato, Nagano 380-8553, Japan

${ }^{g}$ Bruker Japan, 3-9, Moriya-cho, Kanagawa-ku, Yokohama 221-0022, Japan

${ }^{h}$ Division of Liberal Arts, Center for Promotion of Higher Education, Kogakuin University, 2665-1 Nakano, Hachioji, Tokyo 192-0015, Japan

$\dagger$ Electronic supplementary information (ESI) available: Materials, experimental details, and characterization data. CCDC 1552472 (1C), 1885142 (2BE + 2BF), 1484443 (2CE) and 1552473 (2CF). For ESI and crystallographic data in CIF or other electronic format see DOI: 10.1039/c9ra00822e to-head ( $\mathrm{HH})$ /head-to-tail (HT), syn/anti, enantio- and diastereoselectivity of the reactions in solution have prevented further improvement of the usefulness and understanding of the reaction. To overcome these issues, several methodologies for syn/anti and HH/HT selective [2 +2$]$ photodimerization reactions of coumarins in solution have been developed, e.g., Lewis acid catalysis, ${ }^{3}$ supramolecular photocatalysis accomplished by the use of cyclodextrins, ${ }^{4 a}$ hydrazine derivatives, ${ }^{4 b}$ bisurea macrocycles, ${ }^{4 c}$ cucurbit[8]uril, ${ }^{4 d}$ taco-type host-guest complex$\mathrm{es}^{4 e}$ and self-assembled monolayers of coumarin derivatives on gold. ${ }^{4 f}$ For an enantioselective reaction, Tanaka and Fujiwara reported outstanding results of an asymmetric photodimerization of simple coumarin by the use of TADDOL derivatives which gave an anti-HT dimer with excellent enantiomeric excess (up to $96 \%$ ee). ${ }^{5}$ However, to the best of our knowledge, the methodology to synthesis a syn-HT dimer in a diastereoselective manner has yet to be demonstrated. ${ }^{6}$ Herein, we report a novel asymmetric $[2+2]$ photodimerization of chiral coumarin-3-carboxamide which gives only syn-HT dimers along with moderate diastereoselectivity.

We initially conducted $[2+2]$ photodimerization reactions of (S)-4-phenyl-3-(2-oxo-2H-chromene-3-carbonyl)-2-oxazolidinone (1A) in acetone, resulting in recovery of $\mathbf{1 A}$ without any desired dimers, which could be caused by the incredibly poor solubility of $1 \mathrm{~A}$ (Table 1). Next, we tried to use $(S)$-4-isopropyl-3-(2-oxo- $2 \mathrm{H}^{-}$ chromene-3-carbonyl)-2-oxazolidinone (1B), which gave 2BE and 2BF as an inseparable mixture with good yield and the ratio of $2 \mathbf{B E}$ to $2 \mathrm{BF}$ as $55: 45$. X-ray crystallographic analysis provided a structure of $50: 50$ diastereomeric mixture of $2 \mathbf{B E}$ and $2 \mathbf{B F}$, which revealed that the reaction had progressed in a syn- and HT-selective manner (Fig. 1). We also used (S)-4-benzyl-3-(2-oxo-2H-chromene-3carbonyl)-2-oxazolidinone (1C) (entry 3) instead of $\mathbf{1 B}$. 
As a result, solubility of the chiral coumarin and the diastereomeric ratio of dimers were improved to give $2 \mathbf{C E}$ and $2 \mathbf{C F}$ with the ratio of $63: 37$ in 99\% yield. Photodimer 2CE and $2 \mathbf{C F}$ were separable. syn-HT structures of $2 \mathbf{C E}$ and $2 \mathrm{CF}$ were also successfully determined by X-ray crystallographic analyses. When the reaction was carried out in toluene (entry 4), syn-HT 2CE and syn-HT 2CF were obtained in excellent yield with the same diastereomeric ratio as the reaction in acetone (entry 3 versus entry 4). The yield of syn-HT 2CE and syn-HT 2CF was decreased by the use of $\alpha, \alpha, \alpha$-trifluorotoluene $\left(\mathrm{CF}_{3} \mathrm{C}_{6} \mathrm{H}_{5}\right)$ as a reaction solvent, which was probably due to low solubility of $1 \mathrm{C}$ in $\mathrm{CF}_{3} \mathrm{C}_{6} \mathrm{H}_{5}$ (entry 5). Solubility enhancement of $\mathbf{1 C}$ had a good impact on increasing the reaction rate by the use of $\mathrm{CH}_{2} \mathrm{Cl}_{2}, \mathrm{CHCl}_{3}$ and $\mathrm{CH}_{3} \mathrm{CN}$ as reaction solvents, but decreased the diastereoselectivity as compared to the reaction in toluene (entries 6-8 versus entries 3 and 4). As far as we know, there is only one example of a non-photochemical reaction, which is the highly diastereoselective 1,3-dipolar cycloaddition reaction, by the use of a chiral oxazolidinone-functionalized substrate in the absence of Lewis acid as reported by Sibi and co-workers. ${ }^{7} \mathrm{We}$ were intrigued by induction of moderate diastereoselectivity in the absence of a chelating agent Lewis acid. Therefore, we tried to add Lewis acid in an effort to improve diastereoselectivity by utilizing a chelation control agent. ${ }^{8}$ Regarding a role for the Lewis acid in $[2+2]$ photodimerization reactions, Lewis and coworkers reported the $[2+2]$ photodimerization reaction of

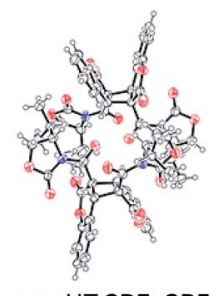

syn-HT 2BE+2BF

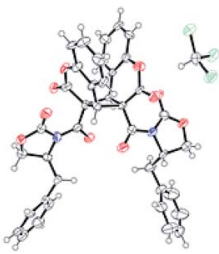

syn-HT 2CE

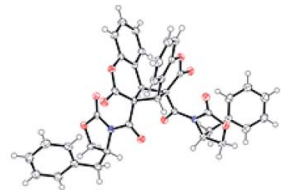

syn-HT 2CF
Fig. 1 ORTEP drawing of photodimers: the inclusion of chloroform was observed in syn-HT 2CE.

achiral coumarin in the presence of $\mathrm{BF}_{3} \cdot \mathrm{OEt}_{2}$ to give the syn-HT dimer as a single product. ${ }^{3}$ In the search for a good chelating Lewis acid for 3-acyl-2-oxazolidinone derivatives, we tested $\mathrm{Zn}\left(\mathrm{ClO}_{4}\right)_{2} \cdot 6 \mathrm{H}_{2} \mathrm{O}$ for the reaction of $\mathbf{1 B}$ (entry 9). ${ }^{9} \mathrm{~A}$ noncoordination solvent toluene was used for the reaction. As a result, the reaction of $\mathbf{1 B}$ was inhibited by the addition of $\mathrm{Zn}$ (II) salt to give $\mathbf{2 B E}$ and $\mathbf{2 B F}$ with recovery of $\mathbf{1 B}$ (entry 9).

Interestingly, the reaction of $\mathbf{1 C}$ in the presence of $\mathrm{Zn}\left(\mathrm{ClO}_{4}\right)_{2} \cdot 6 \mathrm{H}_{2} \mathrm{O}$ in toluene proceeded to achieve an improvement of yields and diastereomeric ratio of syn-HT dimers (2CE : $2 \mathbf{C F}=75: 25$, entry 10). The use of acetone as a reaction solvent and $\mathrm{Zn}\left(\mathrm{ClO}_{4}\right)_{2} \cdot 6 \mathrm{H}_{2} \mathrm{O}$ as a Lewis acid diminished the yield of syn-HT 2CE and syn-HT 2CF (entry 11). The reaction of 1C in the presence of $\mathrm{BF}_{3} \cdot \mathrm{OEt}_{2}$ in toluene showed a slightly improved diastereomeric ratio in comparison with the reaction

Table 1 [2 +2$]$ Photodimerization reactions of chiral coumarin-3-carboxamides

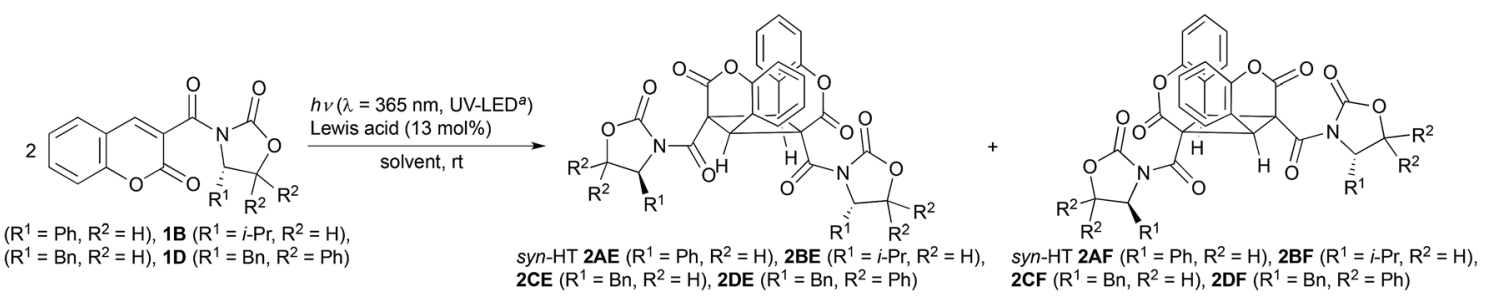

$1 A\left(R^{1}=P h, R^{2}=H\right), 1 B\left(R^{1}=i-P r, R^{2}=H\right)$ $1 C\left(R^{1}=B n, R^{2}=H\right), 1 D\left(R^{1}=B n, R^{2}=P h\right)$
syn-HT 2AE $\left(\mathrm{R}^{1}=\mathrm{Ph}, \mathrm{R}^{2}=\mathrm{H}\right), 2 \mathrm{BE}\left(\mathrm{R}^{1}=i-\mathrm{Pr}, \mathrm{R}^{2}=\mathrm{H}\right)$ SCE $\left(R^{1}=B n, R^{2}=H\right), 2 D E\left(R^{1}=B n, R^{2}=P h\right)$
$2 A E\left(R^{1}=P h, R^{2}=H\right), 2 B\left(R^{1}=i-P r\right.$,
2
syn-HT 2AF $\left(R^{1}=P h, R^{2}=H\right), 2 B F\left(R^{1}=i-P r, R^{2}=H\right)$, $2 C F\left(R^{1}=B n, R^{2}=H\right), 2 D F\left(R^{1}=B n, R^{2}=P h\right)$

\begin{tabular}{|c|c|c|c|c|c|c|}
\hline Entry & Coumarin & Solvent & Additive & Time/h & Yield $^{b} / \%$ & Diastereomeric ratio $^{c}$ \\
\hline 1 & $\mathbf{1 A}$ & Acetone & No & 48 & 0 & $-(2 \mathbf{A E}):-(\mathbf{2 A F})$ \\
\hline 2 & $1 B$ & Acetone & No & 48 & 83 & 55 (2BE) : 45 (2BF) \\
\hline 3 & $1 \mathrm{C}$ & Acetone & No & 48 & 99 & $63($ 2CE) : 37 (2CF) \\
\hline 4 & $1 \mathrm{C}$ & Toluene & No & 48 & 90 & $63(\mathbf{2 C E}): 7$ (2CF) \\
\hline 5 & $1 \mathrm{C}$ & $\mathrm{CF}_{3} \mathrm{C}_{6} \mathrm{H}_{5}$ & No & 48 & 56 & $59(2 \mathrm{CE}): 41(2 \mathrm{CF})$ \\
\hline 6 & $1 \mathrm{C}$ & $\mathrm{CH}_{2} \mathrm{Cl}_{2}$ & No & 24 & 95 & 61 (2CE) : 39 (2CF) \\
\hline 7 & $1 \mathrm{C}$ & $\mathrm{CHCl}_{3}$ & No & 24 & 96 & $58(2 \mathrm{CE}): 42(2 \mathrm{CF})$ \\
\hline 8 & $1 \mathrm{C}$ & $\mathrm{CH}_{3} \mathrm{CN}$ & No & 24 & 92 & 53 (2CE) : 47 (2CF) \\
\hline 9 & $1 B$ & Toluene & $\mathrm{Zn}\left(\mathrm{ClO}_{4}\right)_{2} \cdot 6 \mathrm{H}_{2} \mathrm{O}$ & 96 & $24^{d}$ & $70(2 \mathrm{BE}): 30(\mathbf{2 B F})$ \\
\hline 10 & $1 \mathrm{C}$ & Toluene & $\mathrm{Zn}\left(\mathrm{ClO}_{4}\right)_{2} \cdot 6 \mathrm{H}_{2} \mathrm{O}$ & 48 & 92 & 75 (2CE) : 25 (2CF) \\
\hline 11 & $1 \mathrm{C}$ & Acetone & $\mathrm{Zn}\left(\mathrm{ClO}_{4}\right)_{2} \cdot 6 \mathrm{H}_{2} \mathrm{O}$ & 48 & 72 & 75 (2CE) : 25 (2CF) \\
\hline 12 & $1 \mathrm{C}$ & Toluene & $\mathrm{BF}_{3} \cdot \mathrm{OEt}_{2}$ & 48 & 90 & $70(\mathbf{2 C E}): 30(\mathbf{2 C F})$ \\
\hline 13 & $1 \mathrm{C}$ & Toluene & $\mathrm{Mg}\left(\mathrm{ClO}_{4}\right)_{2}$ & 48 & 72 & 69 (2CE) : 31 (2CF) \\
\hline 14 & $1 \mathrm{C}$ & Toluene & $\mathrm{Ni}\left(\mathrm{ClO}_{4}\right)_{2} \cdot 6 \mathrm{H}_{2} \mathrm{O}$ & 48 & 75 & 67 (2CE) : 33 (2CF) \\
\hline 15 & $1 \mathrm{C}$ & Toluene & $\mathrm{Co}\left(\mathrm{ClO}_{4}\right)_{2} \cdot 6 \mathrm{H}_{2} \mathrm{O}$ & 48 & 51 & $70(\mathbf{2 C E}): 30(\mathbf{2 C F})$ \\
\hline 16 & $1 \mathrm{C}$ & Toluene & $\mathrm{Cu}\left(\mathrm{ClO}_{4}\right)_{2} \cdot 6 \mathrm{H}_{2} \mathrm{O}$ & 48 & 42 & $71(\mathbf{2 C E}): 29(\mathbf{2 C F})$ \\
\hline 17 & $1 \mathrm{C}$ & Toluene & $\mathrm{Fe}\left(\mathrm{ClO}_{4}\right)_{2} \cdot x \mathrm{H}_{2} \mathrm{O}$ & 48 & 77 & $72(\mathbf{2 C E}): 28$ (2CF) \\
\hline 18 & $1 D$ & Toluene & $\mathrm{Zn}\left(\mathrm{ClO}_{4}\right)_{2} \cdot 6 \mathrm{H}_{2} \mathrm{O}$ & 96 & 0 & $-(2 \mathrm{DE}):-(2 \mathrm{CF})$ \\
\hline
\end{tabular}

${ }^{a}$ The external irradiation was directed toward the Pyrex test tube with a working distance of $1 \mathrm{~cm}$. All reactions were degassed by argon bubbling for 15 min prior to irradiation. ${ }^{b}$ Isolated yield. ${ }^{c}$ Determined by ${ }^{1} \mathrm{H}$ NMR. ${ }^{d}$ Recovery of $1 \mathrm{~B}$ in $52 \%$. 

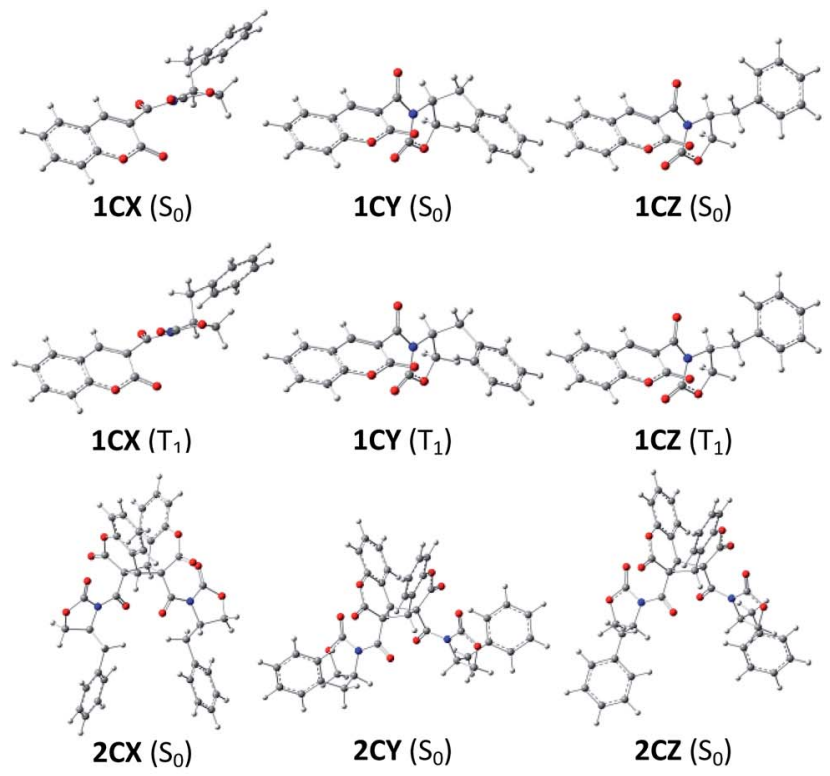

\begin{tabular}{cc}
\hline Compounds & $\Delta E(\mathrm{kcal} / \mathrm{mol})$ \\
\hline $\mathbf{1 C X}\left(\mathrm{S}_{0}\right)$ & 0 \\
$\mathbf{1 C Y}\left(\mathrm{S}_{0}\right)$ & 1.45 \\
$\mathbf{1 C Z}\left(\mathrm{S}_{0}\right)$ & 0.54 \\
$\mathbf{1 C X}\left(\mathrm{T}_{1}\right)$ & 0 \\
$\mathbf{1 C Y}\left(\mathrm{T}_{1}\right)$ & 1.44 \\
$\mathbf{1 C Z}\left(\mathrm{T}_{1}\right)$ & 0.36 \\
$\mathbf{2 C X}\left(\mathrm{S}_{0}\right)$ & 0.14 \\
$\mathbf{2 C Y}\left(\mathrm{S}_{0}\right)$ & 1.30 \\
$\mathbf{2 C Z}\left(\mathrm{S}_{0}\right)$ & 0 \\
\hline
\end{tabular}

Scheme 1 Optimized structures of $1 \mathrm{C}\left(\mathrm{S}_{0}\right.$ and $\left.\mathrm{T}_{1}\right)$ and $2 \mathrm{C}\left(\mathrm{S}_{0}\right)$.

in the absence of $\mathrm{BF}_{3} \cdot \mathrm{OEt}_{2}(\mathbf{2 C E}: \mathbf{2 C F}=70: 30$, entry 12). Other metal perchlorates such as $\mathrm{Mg}, \mathrm{Ni}, \mathrm{Co}, \mathrm{Cu}$ and $\mathrm{Fe}$ slightly improved the $2 \mathbf{C E}: \mathbf{2 C F}$ ratio (entries 13-17). To improve solubility of the chiral coumarin, we prepared 1D having three hydrophobic phenyl groups and used this compound for the photodimerization reaction. However, undesired photodecomposition of 1D occurred (entry 18). Interestingly, no reaction was induced when the reaction of $1 \mathrm{C}$ was performed in the presence of a stoichiometric amount of $\mathrm{Zn}\left(\mathrm{ClO}_{4}\right)_{2} \cdot 6 \mathrm{H}_{2} \mathrm{O}$ as well as $\mathrm{BF}_{3}$ - $\mathrm{OEt}_{2}$. This phenomenon might suggest that the ratio of the metal complex of 1C and metal-free 1C in solution is important for the reaction to progress. ${ }^{3,10}$

To gain insight into the mechanism of complete syn-HT selectivity and moderate diastereoselectivity, we optimized the structure of 1C in toluene using DFT calculations (Scheme 1). ${ }^{11}$ All calculations were performed using the B3LYP hybrid functional and a basis set (6-311G**) level of theory with Gaussian 16. The solvent effect of toluene was modeled via the polarizable continuum model using the integral equation formalism variant (IEFPCM). Three conformers $\mathbf{1 C X}, \mathbf{1 C Y}$ and $\mathbf{1 C Z}$ were generated which are energetically closed. ${ }^{12}$ We revealed that the order of the change in energy among three conformers was $\mathbf{1 C X}$ $\left(\mathrm{S}_{0}\right)<\mathbf{1 C Z}\left(\mathrm{S}_{0}\right)<\mathbf{1 C Y}\left(\mathrm{S}_{0}\right)$. The crystal structure of $\mathbf{1 C}$ was similar to $\mathbf{C Z}$, which indicates that the major conformer involved in the $[2+2]$ photodimerization would be changed between the solution and the crystalline states. ${ }^{13}$

Energies of photodimers $s y n-\mathrm{HH}$, anti-HH and anti-HT in toluene were also optimized by DFT calculation (B3LYP/6$311 \mathrm{G}^{* *}$ ) to explain the exclusive formation of syn-HT dimer, which would be induced predominantly by accommodating the $(S)$-4-benzyl-2-oxazolidinone auxiliary in a favorable direction with a special allowance in the TS (Fig. 2).$^{14}$ Structures of $\mathbf{2 C X}$ and $2 \mathrm{CY}$ were found to correspond to the structures of the cycloadducts syn-HT 2CE and syn-HT 2CF, respectively. It must be noted that $2 \mathrm{CZ}$ is the major diastereomer with a different conformation from that of $2 \mathrm{CY}$. Thus, the order of the change in energy for photodimers was $\mathbf{2} \mathbf{C Z}<\mathbf{2} \mathbf{C X}<\mathbf{2} \mathbf{C Y}$. There was not much difference in energy between $\mathbf{2 C X}$ and $2 \mathbf{C Z}$. Timedependent DFT (TD-DFT) calculations showed that HOMO $\rightarrow$
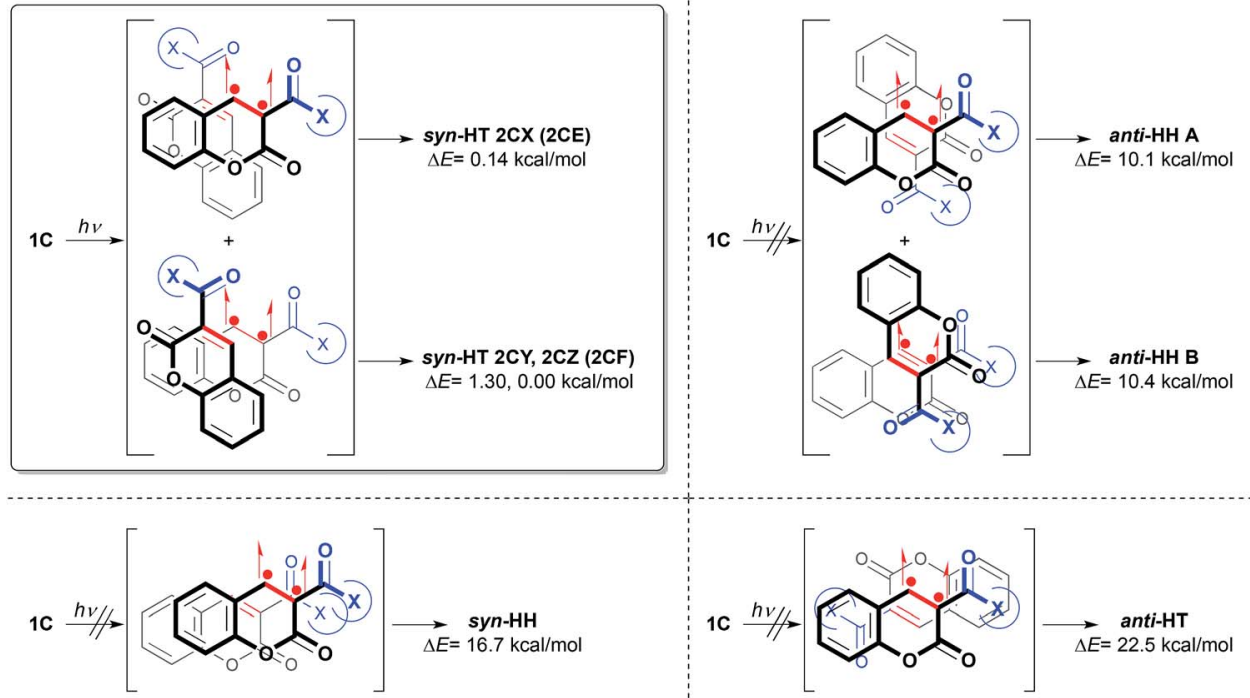

Fig. 2 Exclusive formation of syn-HT dimers caused by the steric hindrance between two chiral coumarins. 


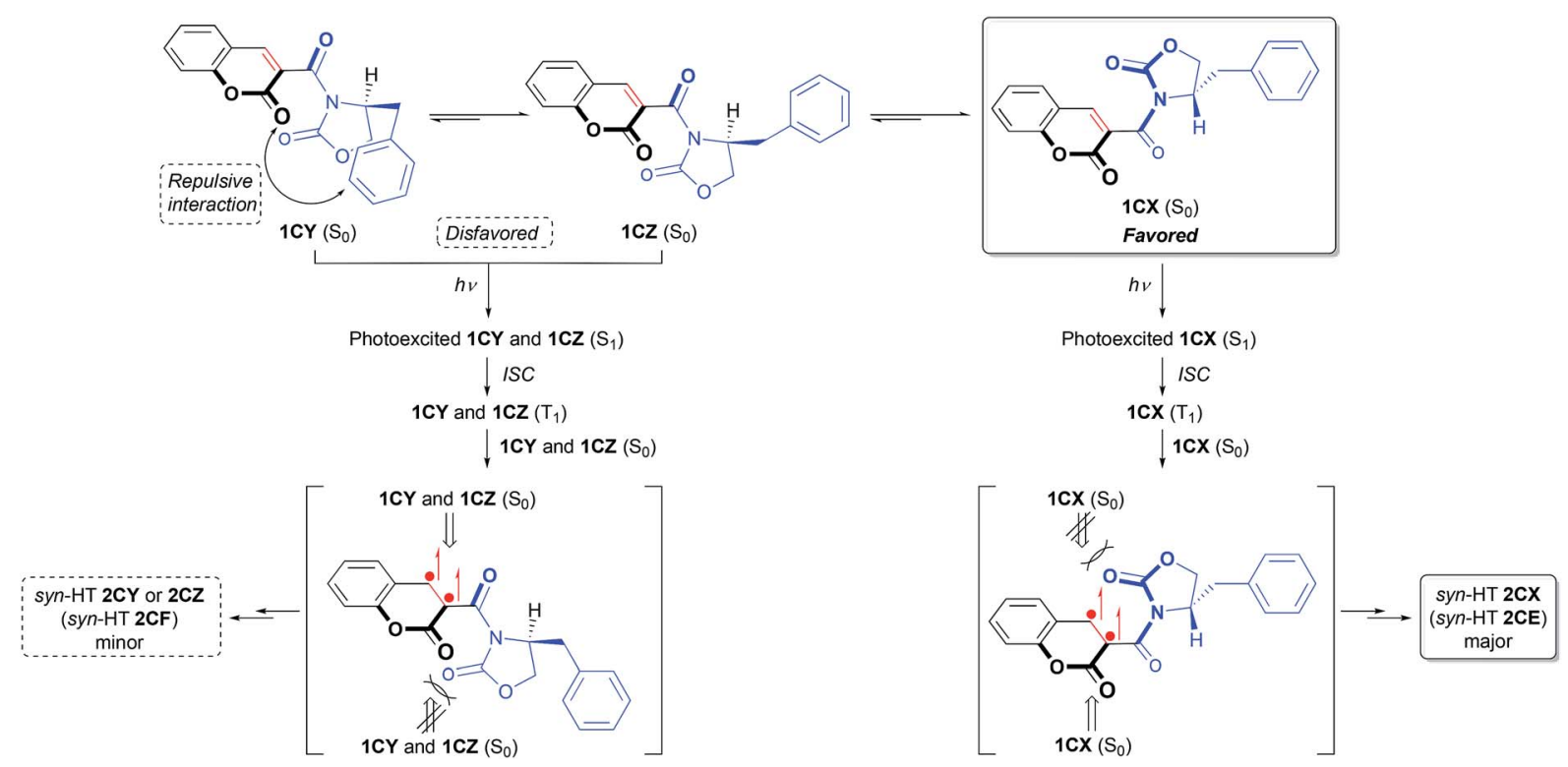

Scheme 2 Proposed mechanism for diastereofacial selectivity.

LUMO transition for each of the three conformers 1CX, 1CY and 1CZ would be best described as a triplet excited state $\left[{ }^{3}(\pi, \pi)^{*}\right]$ $\left(\mathrm{T}_{1}\right)$ for the carbon-carbon double bond of the reaction site with zero oscillator strength (Scheme 2). Therefore, it is suggested that the ground state $\left(\mathrm{S}_{0}\right)$ for each of the three conformers was excited to become a singlet state $\left[{ }^{1}(\pi, \pi)^{*}\right]\left(S_{1}\right)$ followed by intersystem crossing (ISC) to generate $\mathrm{T}_{1}$. Consequently, the order of the change in energy among $\mathrm{T}_{1}$ of the three conformers was also calculated as 1CX $\left(\mathrm{T}_{1}\right)<1 \mathrm{CZ}\left(\mathrm{T}_{1}\right)<\mathbf{1 C Y}\left(\mathrm{T}_{1}\right)$. From the results mentioned above, the $[2+2]$ photodimerization reaction would start from excitation of the most stable comformer $\mathbf{1 C X}\left(\mathrm{S}_{0}\right)$ which preferentially generates $\mathbf{1 C X}\left(\mathrm{T}_{1}\right)$ via ISC of a singlet excited state 1CX $\left(\mathrm{S}_{1}\right)$. The resulting triplet species $\mathbf{1 C X}\left(\mathrm{T}_{1}\right)$ would be subjected to react with $\mathbf{1 C X}\left(\mathrm{S}_{0}\right)$ in syn-HT fashion (discussed below) to give 2CX. The effect of the Lewis acid is unclear at the present time. However, we postulate that the Lewis acid could stabilize $1 \mathrm{CX}$ by a coordination in a bidentate fashion to prevent the conformational change to $\mathbf{1 C Y}$ and $\mathbf{1 C Z}$, which would be induced by a free rotation of the carbon-carbon single bond between the coumarin ring and the 2-oxazolidinone auxiliary. ${ }^{3,8,15,16}$ The moderate diastereoselectivity could be explained by the following process (also depicted in Scheme 2). Two carbonyl groups in the (S)-3-acyl-4-benzyl-2-oxazolidinone auxiliary could be oriented opposite each other to minimize the dipole moment and the electrostatic repulsion. To minimize steric repulsion caused between the benzyl group of the 2-oxazolidinone auxiliary and the carbonyl group of the coumarin ring, the conformational bias leads more favorably toward 1CX rather than 1CY and 1CZ. The carbonyl group including the 2-oxazolidinone ring would serve as a shielding group to prevent approach from the top side, thus affording 2CX, i.e., syn-HT 2CE (Scheme 3).

The reduction of the chiral oxazolidinone moiety was successfully proceeded to give triol $3 .{ }^{17}$ Interestingly, the reduction of chroman-2-one moiety also concomitantly occured with the removal of chiral auxiliary affording $\mathbf{3}$ as a single diastereomer. ${ }^{18}$

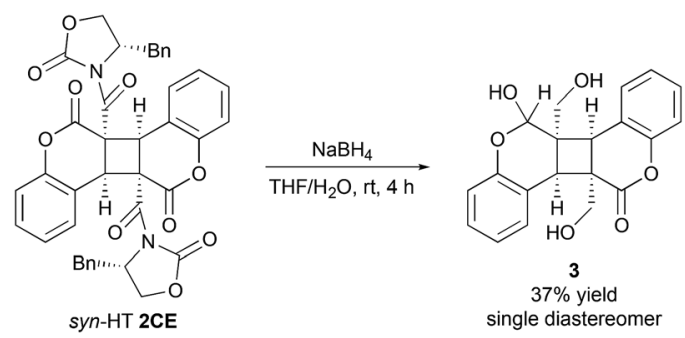

Scheme 3 Removal of the chiral auxiliary with the reduction of chroman-2-one moiety.

In conclusion, we have developed a novel asymmetric photodimerization reaction of chiral coumarin-3-carboxamide which affords syn-HT dimer selectively with a moderate level of diastereoselectivity. Removal of chiral auxiliary was conducted to expand the applicability of the photodimer by the reduction using $\mathrm{NaBH}_{4}$ in $\mathrm{THF}-\mathrm{H}_{2} \mathrm{O}$. Further studies to elucidate the reaction mechanism and for application in the area of medicinal chemistry, drug delivery, and chemical biology are ongoing.

\section{Conflicts of interest}

There are no conflicts to declare.

\section{Acknowledgements}

This work was supported by JSPS KAKENHI Grant numbers JP17K14550 and JP18K05111. The computation was mainly carried out using the computer facilities at Research Institute for Information Technology, Kyushu University. We gratefully thank Ms. Noriko Sato (the Institute of Instrumental Analysis of Kitasato University, School of Pharmacy) for ${ }^{1} \mathrm{H}$ NMR analyses. 


\section{Notes and references}

1 (a) G. S. Hammond, C. A. Stout and A. A. Lamola, J. Am. Chem. Soc., 1964, 86, 3103; (b) N. K. Ray and V. K. Ahuja, Photochem. Photobiol., 1973, 17, 347; (c) D. V. Rao, H. Ulrich, F. A. Stuber and A. A. R. Sayigh, Chem. Ber., 1973, 106, 388; (d) J. Turro, Modern Molecular Photochemistry, University Science Books, 1991, p. 462; (e) T. Wolff and H. Görner, Phys. Chem. Chem. Phys., 2004, 6, 368; $(f)$ S. R. Trenor, A. R. Shultz, B. J. Love and T. E. Long, Chem. Rev., 2004, 104, 3059; (g) H. Görner and T. Wolff, Photochem. Photobiol., 2008, 84, 1224-1230; $(h)$ M. Pattabiraman, J. Sivaguru and V. Ramamurthy, Isr. J. Chem., 2018, 58, 264.

2 (a) N. K. Mal, M. Fujiwara and Y. Tanaka, Nature, 2003, 421, 350; (b) T. M. Guardado-Alvarez, L. S. Devi, M. M. Russell, B. J. Schwartz and J. I. Zink, J. Am. Chem. Soc., 2013, 135, 14000; (c) J. W. Chung, K. Lee, C. Neikirk, C. M. Nelson and R. D. Priestley, Small, 2012, 8, 1693; (d) B. Miska, Med. Chem., 2016, 6, 611; (e) R. Tamae, T. Ueki, Y. Kitazawa, M. Kuzunuki, M. Watanabe, A. M. Akimoto and R. Yoshida, Chem. Mater., 2016, 28, 6401; (f) R. Tamae, T. Ueki, A. M. Akimoto, R. Yoshida, T. Oyama, H. Kokubo and M. Watanabe, $R S C$ Adv., 2018, 8, 3418; $(g)$ K. lliopoulos, O. Krupka, D. Gindre and M. Sallé, J. Am. Chem. Soc., 2010, 132, 14343; (h) M. d'Halluin, J. RullBarrull, E. Le Grognec, D. Jacquemin and F.-X. Felpin, Chem. Commun., 2016, 52, 7672; (i) W. Chen, U. Tong, T. Zeng, C. Streb and Y.-F. Song, J. Mater. Chem. C, 2015, 3, 4388; (j) W. Fan, X. Tong, Q. Yan, S. Fu and Y. Zhao, Chem. Commun., 2014, 50, 13492; (k) E. M. Draper, T. O. McDonald and D. J. Adams, Chem. Commun., 2015, 51, 12837; (l) Y. Chen, K. Saigo, N. Yonezawa, K. Tachibana and M. Hasegawa, Bull. Chem. Soc. Jpn., 1987, 60, 3341.

3 F. D. Lewis, D. K. Howard and J. D. Oxman, J. Am. Chem. Soc., 1983, 105, 3344.

4 (a) J. N. Moorthy, K. Venkatesan and R. G. Weiss, J. Org. Chem., 1992, 57, 3292; (b) W. G. Skene, E. Couzigné and J.-M. Lehn, Chem.-Eur. J., 2003, 9, 5560; (c) J. Yang, M. B. Dewal and L. S. Shimizu, J. Am. Chem. Soc., 2006, 128, 8122; (d) N. Barooah, B. C. Pemberton and J. Sivaguru, Org. Lett., 2008, 10, 3339; (e) P. Wei, H. Wang, K. Jie and F. Huang, Chem. Commun., 2017, 53, 1688; (f) W. Li, V. Lynch, H. Thompson and M. A. Fox, J. Am. Chem. Soc., 1997, 119, 7211.

5 K. Tanaka and T. Fujiwara, Org. Lett., 2005, 7, 1501.

6 Synthesis of syn-HT dimer from simple coumarin without asymmetric induction was achieved by taking advantage of
Lewis acid catalysis (ref. 3), solvent effects (ref. $1 e$ and $f$ ) and supramolecular catalysis (ref. $4 c$ and $d$ ).

7 M. P. Sibi, T. Soeta and C. P. Jasperse, Org. Lett., 2009, 11, 5366.

8 D. A. Evans, K. T. Chapman and J. Bisaha, J. Am. Chem. Soc., 1988, 110, 1238.

9 (a) S. Kanemasa, Y. Oderaotoshi, H. Yamamoto, J. Tanaka and E. Wada, J. Org. Chem., 1997, 62, 6454; (b) S. Kanemasa, Y. Oderaotoshi, S. Sakaguchi, H. Yamamoto, J. Tanaka, E. Wada and D. P. Curran, J. Am. Chem. Soc., 1998, 120, 3074.

10 Lewis and co-workers revealed that increasing the amount of Lewis acid caused a lower quantum yield $(\Phi)$ of the photodimerization. See ref. 3.

11 M. J. Frisch, et al., Gaussian 16, Revision A.03, Gaussian, Inc., Wallingford CT, 2016.

12 It was difficult to distinguish three conformers of chiral coumarins $1 \mathrm{CX}, 1 \mathrm{CY}$ and $1 \mathrm{CZ}$ in $\mathrm{CD}_{3} \mathrm{C}_{6} \mathrm{D}_{5}$ and $\left(\mathrm{CD}_{3}\right)_{2} \mathrm{CO}$ at room temperature by $1 \mathrm{D}{ }^{1} \mathrm{H}$ NMR and $2 \mathrm{D}$ rotating-frame Overhauser spectroscopy (ROESY) NMR measurements. While conducting variable-temperature (VT) NMR measurements, chiral coumarin 1C precipitated out under low temperature because of its low solubility.

13 See the ESI $\dagger$ for the crystal structure of $\mathbf{1 A}$.

14 See the ESI $\dagger$ for the experimental and the computational details and results.

15 A small extent of downfield-shifts for the H-4 and C-4 of the coumarin ring of 1C was observed in the presence of $\mathrm{BF}_{3} \cdot \mathrm{OEt}_{2}$ and $\mathrm{Zn}\left(\mathrm{ClO}_{4}\right)_{2} \cdot 6 \mathrm{H}_{2} \mathrm{O}$ (1 equiv.) by ${ }^{1} \mathrm{H}$ and ${ }^{13} \mathrm{C}$ NMR spectroscopic analyses. Absorption of $1 \mathrm{C}$ at $287 \mathrm{~nm}$ was enhanced slightly with an increasing amount of $\mathrm{Zn}\left(\mathrm{ClO}_{4}\right)_{2} \cdot 6 \mathrm{H}_{2} \mathrm{O}$. See the ESI $\dagger$ for the spectra.

16 The structure of $1 \mathrm{C} \mathrm{ZnCl}_{2}$ complex was optimized by DFT calculation (B3LYP/6-311G) to show bidentate complexation of $\mathrm{Zn}$ (II) ion between the carbonyl oxygen of coumarin ring and the acyl oxygen of (S)-3-acyl-4-benzyl-2oxazolidinone auxiliary. See the ESI $\uparrow$ for the computational results.

17 (a) M. Prashad, W.-C. Shieh and Y. Liu, Tetrahedron, 2016, 72, 17; (b) Y. Hashimoto, K. Itoh, A. Kakehi, M. Shiro and H. Suga, J. Org. Chem., 2013, 78, 6182.

18 The structure of 3 was assigned by means of NMR analyses $\left({ }^{1} \mathrm{H}, \quad{ }^{13} \mathrm{C}, \quad{ }^{1} \mathrm{H}-{ }^{1} \mathrm{H} \quad \mathrm{COSY}, \mathrm{HSQC}\right.$ and $\left.\mathrm{HMBC}\right)$. The stereochemistry of C-2 of chroman-2-ol moiety was not determined, albeit a single diastereomer. See the $\mathrm{ESI} \dagger$ for the spectra. 